\title{
Preventive effects of Flos Perariae (Gehua) water extract and its active ingredient puerarin in rodent alcoholism models
}

\author{
Zaijun Zhang ${ }^{1}$, Sha Li $i^{*}$, Jie Jiang ${ }^{1}$, Pei Yu', Jing Liang², Yuqiang Wang ${ }^{1 *}$
}

\begin{abstract}
Background: Radix Puerariae is used in Chinese medicine to treat alcohol addiction and intoxication. The present study investigates the effects of Flos puerariae lobatae water extract (FPE) and its active ingredient puerarin on alcoholism using rodent models.

Methods: Alcoholic animals were given FPE or puerarin by oral intubation prior or after alcohol treatment. The loss of righting reflex (LORR) assay was used to evaluate sedative/hypnotic effects. Changes of gama-aminobutyric acid type $A$ receptor $\left(G A B A_{A} R\right)$ subunits induced by alcohol treatment in hippocampus were measured with western blot. In alcoholic mice, body weight gain was monitored throughout the experiments. Alcohol dehydrogenase $(\mathrm{ADH})$ levels in liver were measured.

Results: FPE and puerarin pretreatment significantly prolonged the time of LORR induced by diazepam in acute alcoholic rat. Puerarin increased expression of gama-aminobutyric acid type A receptor alpha1 subunit and decreased expression of alpha4 subunit. In chronic alcoholic mice, puerarin pretreatment significantly increased body weight and liver ADH activity in a dose-dependent manner. Puerarin pretreatment, but not post-treatment, can reverse the changes of gama-aminobutyric acid type A receptor subunit expression and increase ADH activity in alcoholism models.
\end{abstract}

Conclusion: The present study demonstrates that FPE and its active ingredient puerarin have preventive effects on alcoholism related disorders.

\section{Background}

Alcoholism is a major social, economic and public health problem with profound impacts on brain functions and behaviors [1], exhibiting a variety of symptoms such as hyperexcitability, anxiety, insomnia, agitation and sometimes seizures [2,3]. When alcohol-dependent patients stop drinking, alcohol withdrawal syndromes (AWS) may develop with symptoms of hyperexcitability, anxiety and sleep disorders. The severity of alcohol dependence is positively correlated to the number of intoxication and withdrawal cycles [4]. These clinical findings are supported by studies in rodents $[5,6]$.

\footnotetext{
*Correspondence: tlisha@jnu.edu.cn; yuqiangwang2001@yahoo.com 'Institute of New Drug Research and Guangdong Province Key Laboratory of Pharmacodynamic Constituents of Traditional Chinese Medicine \& New Drug Research, Jinan University College of Pharmacy, Guangzhou 510632, PR China

Full list of author information is available at the end of the article
}

Chinese herbal medicines such as Radix Puerariae (Gegen), Flos Puerariae (Gehua) and Hovenia dulcis (Zhiju) and Chinese medicine formulae such as Gehuajiexing Tang, Zhige Yin and Wuling San are used to relieve alcohol hangover [7]. Other natural products such as ginseng, mung bean, rice bean, radish and dandelion are also used as hangover remedies in folk medicine [8].

Radix Pueraria belongs to the genus Pueraria which includes about 20 species. Keung et al. demonstrated that a crude extract of Radix Puerariae suppressed ethanol intake of the ethanol-preferring golden Syrian hamsters and identified daidzin and daidzein as the main active components [9]. A population of male and female 'heavy' alcohol drinkers treated with Radix Pueraria extract significantly reduced their beer consumption [10]. The underlying mechanism which may be related
Ciomed Central

() 2010 Zhang et al; licensee BioMed Central Ltd. This is an Open Access article distributed under the terms of the Creative Commons Attribution License (http://creativecommons.org/licenses/by/2.0), which permits unrestricted use, distribution, and reproduction in any medium, provided the original work is properly cited. 
to both alcohol metabolism and the reward circuits in the brain [11].

Isoflavones including daidzein, daidzin and puerarin are active compounds of Pueraria. Daidzin reduced alcohol consumption in laboratory animals [12,13] by raising the monoamine oxidase $(\mathrm{MAO}) /$ mitochondrial aldehyde dehydrogenase (ALDH) activity ratio [13]. Puerarin reduced voluntary alcohol intake and alcohol withdrawal symptoms in alcohol preferring (P) rats [14]. However, the effects of puerarin on central nervous system and liver metabolism are not clearly understood.

$\mathrm{GABA}_{\mathrm{A}} \mathrm{R}$ and $\mathrm{ADH}$ are important pharmacological concerns in alcoholism $[15,16]$. The changes in levels of several $\mathrm{GABA}_{\mathrm{A}} \mathrm{R}$ subunits [17] caused by alcohol are accompanied by behavioral disorders, e.g., loss of righting reflex (LORR) [17-19]. The primary pathway of alcohol metabolism involves oxidation to acetaldehyde, catalyzed by $\mathrm{ADH}$, and followed by further oxidation to acetate, catalyzed by ALDH [20]. Therefore, ADH is one of the most important enzymes for decreasing alcohol concentration in the body.

The present study investigates the preventive effects of Flos Puerariae extract (FPE) and its main active component puerarin in acute and chronic alcohol intoxicated animals.

\section{Methods}

\section{FPE preparation}

Flos Puerariae was purchased from a local Chinese medicine shop and authenticated by an investigator (JJ) in pharmaceutical botany. The authentication procedure included appearance identification of raw material and comparison of chemical constituents which have described in Zhong-Yao-Zhi [21]. A voucher herbarium specimen of the material used in this study was deposited as specimen No.125 in the Herbarium of the College of Pharmacy, Jinan University (PR China). The crude herb (300 g) was boiled for two hours at $100^{\circ} \mathrm{C}$ in $1500 \mathrm{ml}$ distilled water. The supernatant was collected after centrifugation and concentrated to $1 \mathrm{~g} / \mathrm{ml}$. Fourteen (14) chemical standards, namely 4'-O-glucopyranoside, 3'-methyoxy-4'-O-glucopyranoside, 4',7-O-glucopyranoside, puerarin, 6'-O-xylosylpuerarin, mirificin, daidzin, 3'-methoxypuerarin, genistin, sophoraside A, ononin, daidzein, genistein and formononetin, were purchased from the National Institute for the Control of Pharmaceutical and Biological Products, Beijing, PR China.

\section{Quality control of FPE}

The qualitative analysis of FPE was performed on an Agilent 1200 Series Reverse-Phase Liquid Chromatography (RPLC) system (Agilent Technologies, Germany) equipped with a microvacuum degasser, a high pressure binary pump, an autosampler, a column compartment coupled with a carrier for heat exchanger $(1.6 \mu \mathrm{l})$, a diode array detector connected to Masshunter software (A02.02, Agilent Technologies, Germany). A Zorbax SB C18 column $(4.6 \mathrm{~mm} \times 50 \mathrm{~mm}, 1.8 \mu \mathrm{m}$, Agilent Technologies, Germany) was used. The mobile phase consisted of A ( $0.1 \%$ formic acid) and B (methanol) with gradient elution: 0-3 minutes, $20-30 \% \mathrm{~B}$; $3-4$ minutes, $30-32 \% \mathrm{~B}$; 4-8 minutes, $32-57 \% \mathrm{~B}$. Flow rate was $2.0 \mathrm{ml}$ per minute and the injection volume was $4 \mu \mathrm{l}$. The column temperature was set at $46^{\circ} \mathrm{C}$. Peaks were detected at $250 \mathrm{~nm}$.

\section{Animals}

Male Sprague-Dawley rats (body weight 300-350 g) and male $B A L B / C$ mice (body weight $30-35 \mathrm{~g}$ ) were obtained from the Experimental Animal Center of Guangdong Province, China (SPF grade, Certificate No. 2005A047, 2006A059). Rats in acute alcoholic experiments were divided into five groups of six (6) animals per group. Chronic alcoholic mice were also divided into five groups of eight (8) animals per group. All animals were kept on a 12 hour/12 hour light/dark cycle under controlled temperature and humidity with ad lib access to food and water. The animal experiments were approved by the Animal Research Ethics Committee, Jinan University.

\section{Acute alcoholic rat model}

A dose of $25 \%(\mathrm{v} / \mathrm{v})$ alcohol was given by intragastric administration, $2 \mathrm{ml}$ per $100 \mathrm{~g}$ body weight, 30 minutes before or after drug treatment. FPE or puerarin was given $1 \mathrm{ml} / 100 \mathrm{~g}$ or $500 \mathrm{mg}$ per $\mathrm{kg}$ body weight respectively. After two days of withdrawal, Loss of Righting Reflex (LORR) assay was used to assess the drug's protective effects. Rats were then sacrificed and their hippocampi were dissected for $\mathrm{GABA}_{\mathrm{A}} \mathrm{R}$ subunit analysis using western blot.

\section{Chronic alcoholic mouse model}

Alcohol $(25 \%, \mathrm{v} / \mathrm{v})$ was given by intragastric administration, $0.2 \mathrm{ml}$ per $10 \mathrm{~g}$ body weight, 30 minutes before or after puerarin treatment $250 \mathrm{mg}$ and $500 \mathrm{mg}$ per $\mathrm{kg}$ body weight once a day for 12 days. Body weight of mice was monitored every two days. At the end of experiment, mice were sacrificed and their livers were dissected for Alcohol dehydrogenase (ADH) assay.

\section{Diazepam-induced LORR assay}

Two days after alcohol intoxication and withdrawals, all animals received an intraperitoneal injection of diazepam (30 mg per kg body weight). LORR and recovery of the righting reflex were observed. After each injection, animals were placed in a supine position in a cage with wire lids. LORR was recorded as the time at which the 
animal was unable to turn itself. Animals were left in the supine position until recovery of the righting reflex. Recovery of the righting reflex was defined as the time that elapsed until the animal was able to right itself three times in 60 seconds. The time to regain the righting reflex was recorded for each animal.

\section{Protein sample preparation and western blot analysis}

After the LORR test, rats were anesthetized and tissues were separated. Individual hippocampi were dissected on ice from each rat brain. P2 membrane fractions were prepared by homogenization, low-speed centrifugation in $0.32 \mathrm{M}$ sucrose and then centrifugation $(\times 12,000 \mathrm{~g}$, Beckman J2-21 centrifuge, Beckman Instruments, Germany) of the supernatant for 20 minutes. The pellet was resuspended and washed in 20 volumes of phosphate-buffered saline (PBS, $150 \mathrm{mM} \mathrm{NaCl}, 10 \mathrm{mM} \mathrm{Na} 2 \mathrm{HPO}_{4} / \mathrm{NaH}_{2} \mathrm{PO}_{4}$, $\mathrm{pH7.4)}$. The final pellet was resuspended in five volumes of PBS and protein concentration was determined with Bradford assay kit (Bio-Rad Laboratories, USA).

Aliquots of $40 \mu \mathrm{g}$ of protein from each sample were separated on 10\% SDS-polyacrylamide gel electrophoresis. Then the proteins were transferred to polyvinylidene difluoride membranes. Blots were stained with anti-peptide $\alpha 1$ or $\alpha 4$ antibodies (1:1000, Santa Cruz Biotechnology, USA) followed by horseradish peroxidase-conjugated anti-rabbit antibodies (1:2000, Zymed laboratories, USA) or anti-goat IgG (1:500, Vector laboratories, Canada). Bands were detected by DAB staining (Sigma, USA). Beta-actin antibody (1:1000,
Santa Cruz Biotechnology, USA) was used to detect endogenous standard for normalization. The bands from various groups corresponding to the appropriate molecular weight for each subunit were analyzed and values were compared using densitometric measurements with image analysis system.

\section{ADH assay}

At the end of chronic alcoholic treatment, mice were sacrificed and livers were dissected on ice. Liver homogenates were prepared with manual homogenization in a $2 \mathrm{~mL}$ glass pestal and centrifugation $(\times 3000 \mathrm{~g}$, Beckman J2-21 centrifuge, Beckman Instruments, Germany) for 10 minutes. Supernatants were collected for ADH determination. ADH assay kit was purchased from Nanjing Jiancheng Biological Laboratory (China) and the experiment was performed according to the manufacturer's instructions. Briefly, oxidized form of nicotinamideadenine dinucleotide (NAD) was added to the liver sample. The absorbance of the reaction mixture was recorded at $340 \mathrm{~nm}$, and $\mathrm{ADH}$ activity was calculated from the absorbance value and protein content. ADH activity was expressed in unit per $\mathrm{mg}$ protein $(\mathrm{U} / \mathrm{mg})$, i.e. $1 \mathrm{U} / \mathrm{mg}$ means that $\mathrm{ADH}$ yields $1 \mathrm{nmol}$ product with $1 \mathrm{mg}$ protein per minute at $37^{\circ} \mathrm{C}$.

\section{Statistical analysis}

Data were expressed as mean \pm SD for the number $(n)$ of animals in each group. ANOVA and Tukey post-test were performed to determine the significant differences
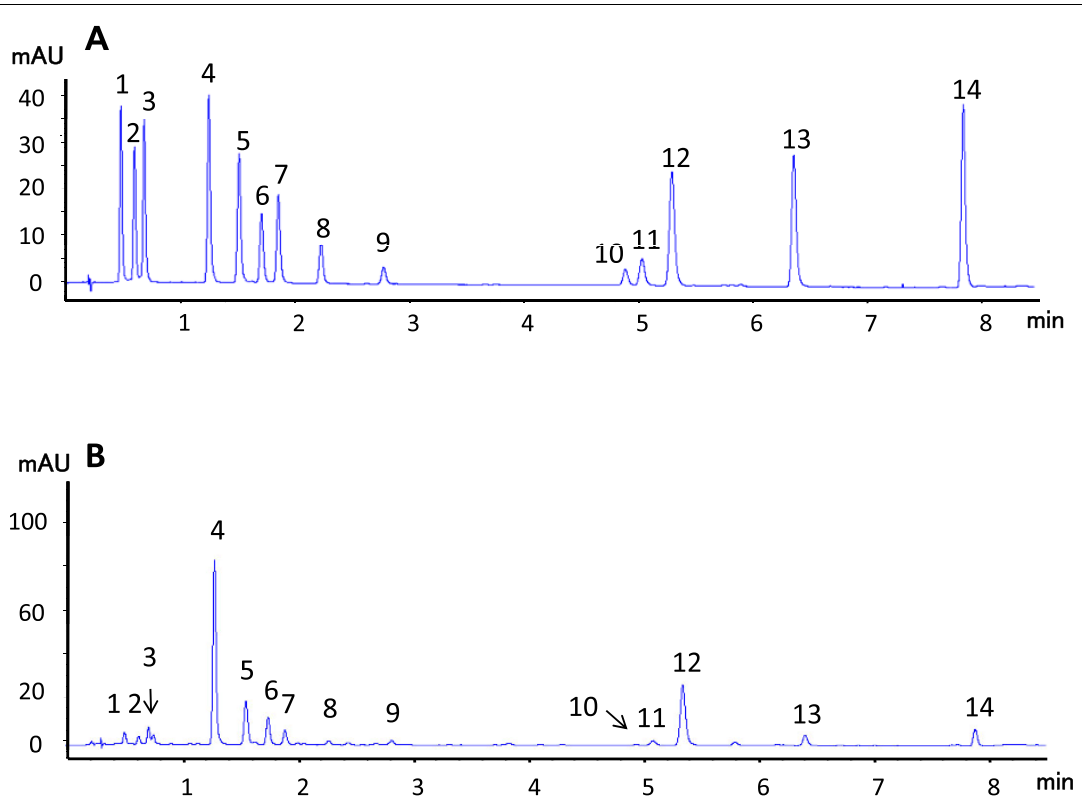

Figure 1 Typical RRLC chromatograms of mixed standards (A) and FPE (B). (1) 4'-O-glucopyranoside, (2) 3'-methyoxy-4'-O-glucopyranoside, (3) 4',7-O-glucopyranoside, (4) puerarin, (5) 6"-O-xylosylpuerarin, (6) mirificin, (7) daidzin, (8) 3'-methoxypuerarin, (9) genistin, (10) sophoraside A, (11) ononin, (12) daidzein, (13) genistein, (14) formononetin. 
between various groups using GraphPad Prism 5.0 software (GraphPad Software, USA). $P$-values of $<0.05$ were considered statistically significant.

\section{Results}

Figure 1 shows the RPLC chromatograms of some standards including puerarin in standard solution and in FPE. Fourteen (14) constituents were identified with RPLC fingerprinting as 4'-O-glucopyranoside, 3'-methyoxy-4'-O-glucopyranoside, 4',7-O-glucopyranoside, puerarin, 6'-O-xylosylpuerarin, mirificin, daidzin, 3'-methoxypuerarin, genistin, sophoraside A, ononin, daidzein, genistein and formononetin. Among them, the abundance of puerarin was highest. This RPLC fingerprinting system can be employed as a tool for FPE quality assurance.

As shown in Figure 2, LORR induced by diazepam significantly decreased $[P=0.0003]$ in acute alcoholic rats (alcohol + saline group). The duration of diazepaminduced LORR was about 60 minutes in normal rats (saline + saline group, Figure 2); however, LORR of the acute alcoholic rats was at $9.8 \pm 3.27$ minutes (Figure 2) which was significantly different from that of the normal rats $[P=0.0003]$. FPE and puerarin alone had no significant effect in the duration of LORR in normal rats. Pretreatment with FPE or puerarin significantly recovered the LORR time of the acute alcoholic rats, which went up to $49 \pm 18.64$ and $51.83 \pm 6.11$ minutes respectively, $[P=0.001]$ against alcohol + saline group). However, FPE or puerarin administration post-alcohol treatment did not significantly recover the duration of LORR (Figure 2).

Alcohol intoxication significantly decreased $\mathrm{GABA}_{\mathrm{A}} \mathrm{R}$ $\alpha 1$ subunit expression in the hippocampus (Figure 3 and Figure $4 \mathrm{~A}$ ) whereas $\mathrm{GABA}_{\mathrm{A}} \mathrm{R} \alpha 4$ subunit expression was notably increased (Figures 3 and $4 \mathrm{~B}$ ). These results were consistent with those reported previously by Cagetti et al [17]. Puerarin pretreatment reversed the effects on $\mathrm{GABA}_{\mathrm{A}} \mathrm{R}$ subunit expression changes in alcoholic rats. Puerarin treatment after alcohol administration showed less effect than the puerarin pretreatment.

Alcohol exposure significantly changed weight gain. Specifically, average weight of saline + saline group increased from $20.7 \pm 1.25 \mathrm{~g}$ to $30.36 \pm 2.06 \mathrm{~g}$ while that of alcohol + saline group decreased from $22.52 \pm$ $0.43 \mathrm{~g}$ to $18 \pm 2.88 \mathrm{~g}[P=0.007]$ (Table 1). Animals of puerarin + alcohol group weighed significantly more than those of the alcohol + saline group from day 4 to $12[\mathrm{P}=0.02]$ (Table 1). Puerarin pretreatment prevented body weight loss in alcoholic mice in a dose-dependent manner.
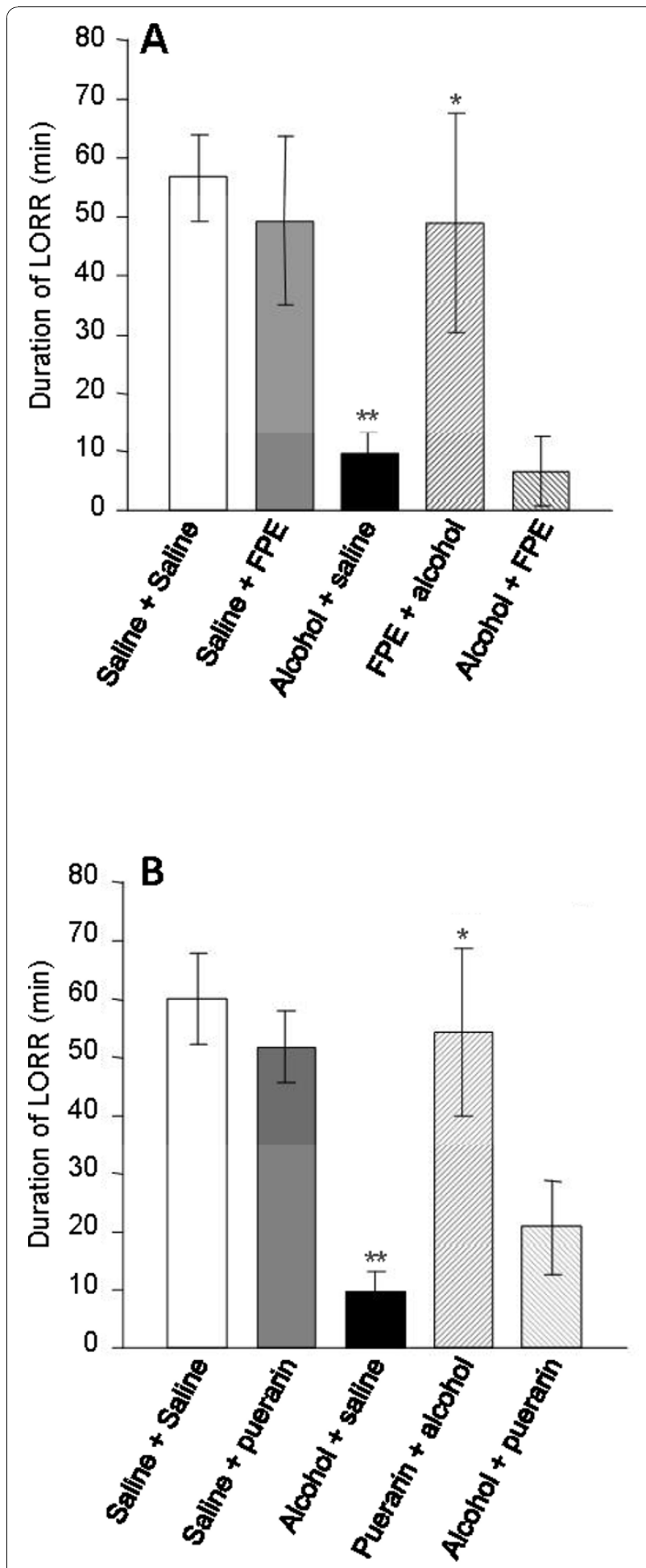

Figure 2 Effects of FPE (A) and puerarin (B) on duration of diazepam induced LORR in normal and alcoholic rats. Data are expressed as mean \pm SD $(n=6)$. ${ }^{*} P<0.05$ compared with 'alcoholt+ saline' treated group; ${ }^{* *} P<0.01$ compared with 'saline+saline' treated group. 


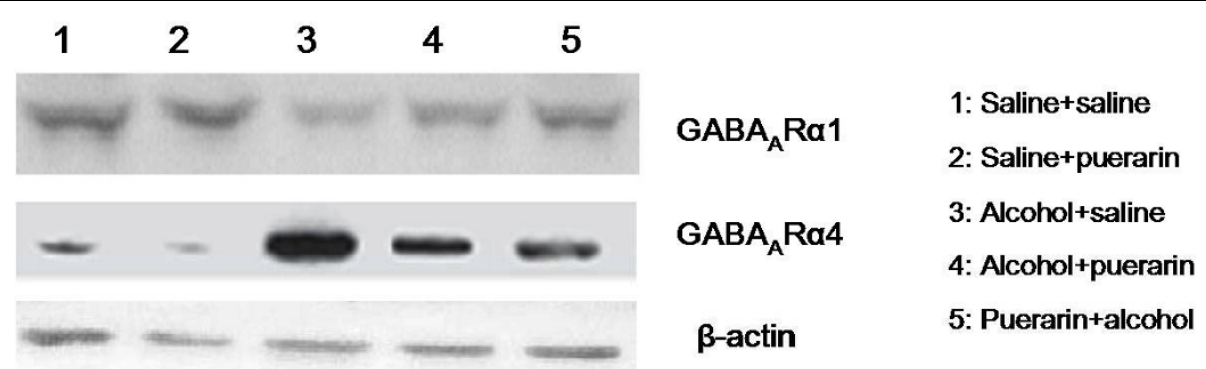

Figure 3 Representative western blot of protein expression of $G A B A_{A} R \alpha 1$ and $\alpha 4$ subunit.

$\mathrm{ADH}$ activity in the alcoholic mice significantly decreased compared to that in normal mice $[P=0.002]$. Puerarin pretreatment reversed this decrease in $\mathrm{ADH}$ activity in the livers of alcoholic mice in a dosedependent manner (Figure 5), suggesting that puerarin may exert its preventive effects in alcoholism through enhancing ADH activity.

\section{Discussion}

Our results demonstrated that pretreatment of FPE or puerarin had significant anti-anxiety effects in the diazepam-induced LORR assay. However, administration of FPE or puerarin after alcohol treatment had less effect. These data suggest that FPE may prevent but not relieve alcoholic disorders.

$\mathrm{GABA}_{\mathrm{A}}$ Rs are the major targets for actions of alcohol $[5,22]$. Our previous studies demonstrated that single dose ethanol intoxication leads to $\mathrm{GABA}_{\mathrm{A}} \mathrm{R}$ plasticity changes such as transcriptionally increases in $\alpha 4$ and $\alpha 2$ and decreases in $\alpha 1$ subunits with preferential insertion of the newly formed $\alpha 4 \beta \gamma 2 \mathrm{GABA}_{\mathrm{A}} \mathrm{R}$ at synapses $[18,19,23]$. To study human alcohol withdrawal and dependence, we established a model for the chronic intermittent ethanol (CIE) intoxication in rats. CIE rats revealed alterations in $\mathrm{GABA}_{\mathrm{A}} \mathrm{R}$ subunit composition and subcellular localization $[18,23,24]$. The present study found that alcohol altered $\mathrm{GABA}_{\mathrm{A}} \mathrm{R}$ composition in an acute alcoholic model, i.e. single dose alcohol treatment increased the expression of $\mathrm{GABA}_{\mathrm{A}} \mathrm{R} \alpha 4$ subunit and decreased the $G_{A B A} R \alpha 1$ subunit. To investigate whether puerarin's LORR recovery effect was due to changes of $\mathrm{GABA}_{\mathrm{A}} \mathrm{R}$ subunit, we determined expression of $\mathrm{GABA}_{\mathrm{A}} \mathrm{R}$ subunits $\alpha 1$ and $\alpha 4$ using western blot. Puerarin pretreatment reversed these changes significantly, that is, upregulated $\alpha 1$ subunit expression and downregulated $\alpha 4$ subunit expression. However, puerarin post-treatment after alcohol was less effective than puerarin pretreatment in reversing transcriptional changes of $\mathrm{GABA}_{\mathrm{A}} \mathrm{R}$ subunits. These data were consistent with puerarin's effect on diazepam-induced LORR recovery.
$\mathrm{ADH}$, which decreases alcohol concentration in the body [20], is one of the most important enzymes in alcohol metabolism. The alcohol concentration in blood increases when ADH activity is decreased, aggravating alcoholic damage to brain, liver and other important organs. Puerarin elevates ADH activity and prevents body weight loss after chronic alcohol exposure. The increase in ADH activity may account for puerarin's detoxification effects against alcohol in liver hepatocytes $[25,26]$. Apart from the detoxification effects, three isoflavonoid compounds, namely puerarin, daidzin and daidzein isolated from Pueraria lobata, suppressed voluntary alcohol consumption in alcohol-preferring rats [27]. It was postulated that the suppression of alcohol reinforcement produced by these compounds is mediated centrally in the brain reward pathway [27,28].

Previous in vitro studies showed that daidzin and daidzein, two isoflavonoids structurely similar to puerarin, were potent inhibitors for mitochondrial low-Km aldehyde dehydrogenase and alcohol dehydrogenase separately $[29,30]$. Therefore, it was postulated at first that these isoflavones might deter alcohol drinking by interfering with alcohol metabolism. However, in vivo study showed that neither blood ethanol nor acetaldehyde concentrations were affected in hamsters injected with daidzein $[27,31]$. These conflicting results warrant further investigations.

Recently, research has focused on the effects of oxidative stress in diseases caused by alcohol [32-36]. When an organism suffered from the stimulation of an oxidant such as alcohol, a large amount of reactive oxygen species (ROS) with neuronal toxicity would be produced and the lipid peroxidation of surrounding tissues increased $[37,38]$. Cao et al. reported that isoflavones and Pueraria extracts containing daidzein, daidzin and puerarin had strong anti-oxidative activities [39]. Antioxidation may be another mechanism underlying the anti-alcoholism activity of puerarin. Further investigations are warranted. 


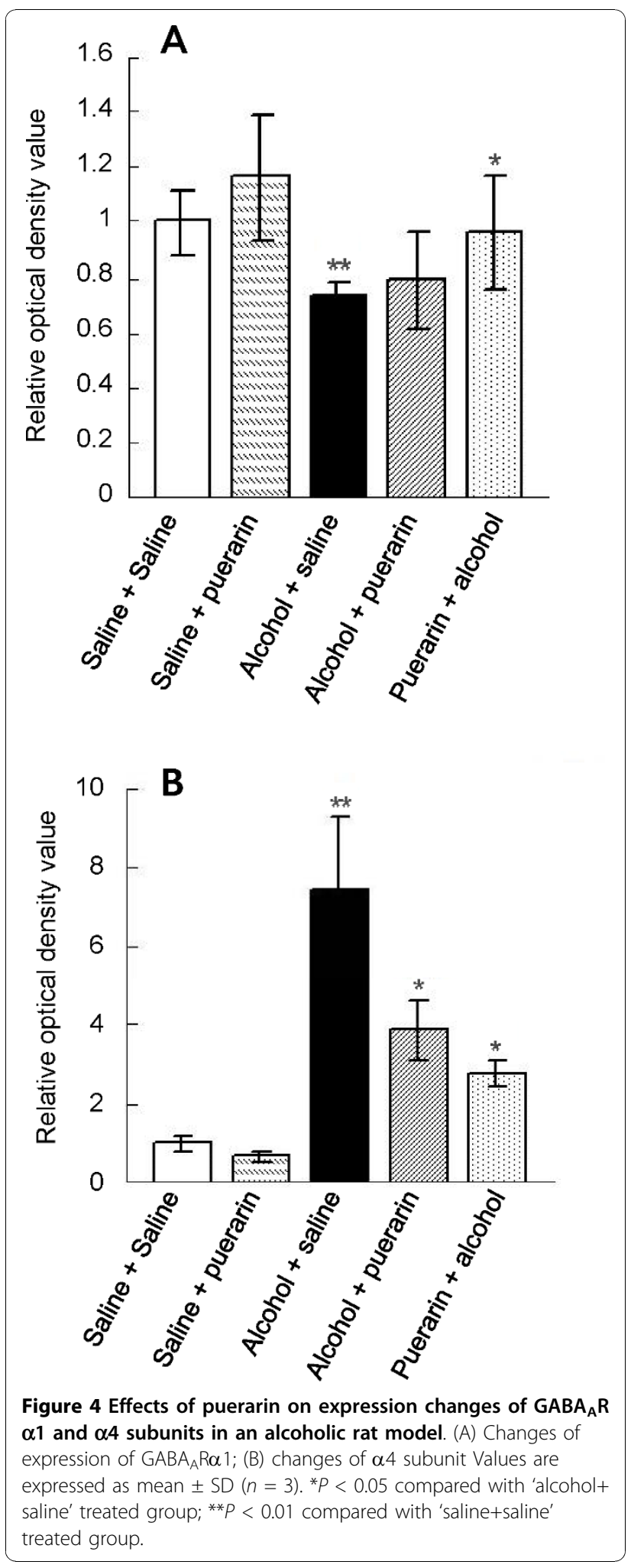

\section{Conclusion}

The present study demonstrates that FPE and its active ingredient puerarin have preventive effects on alcoholism

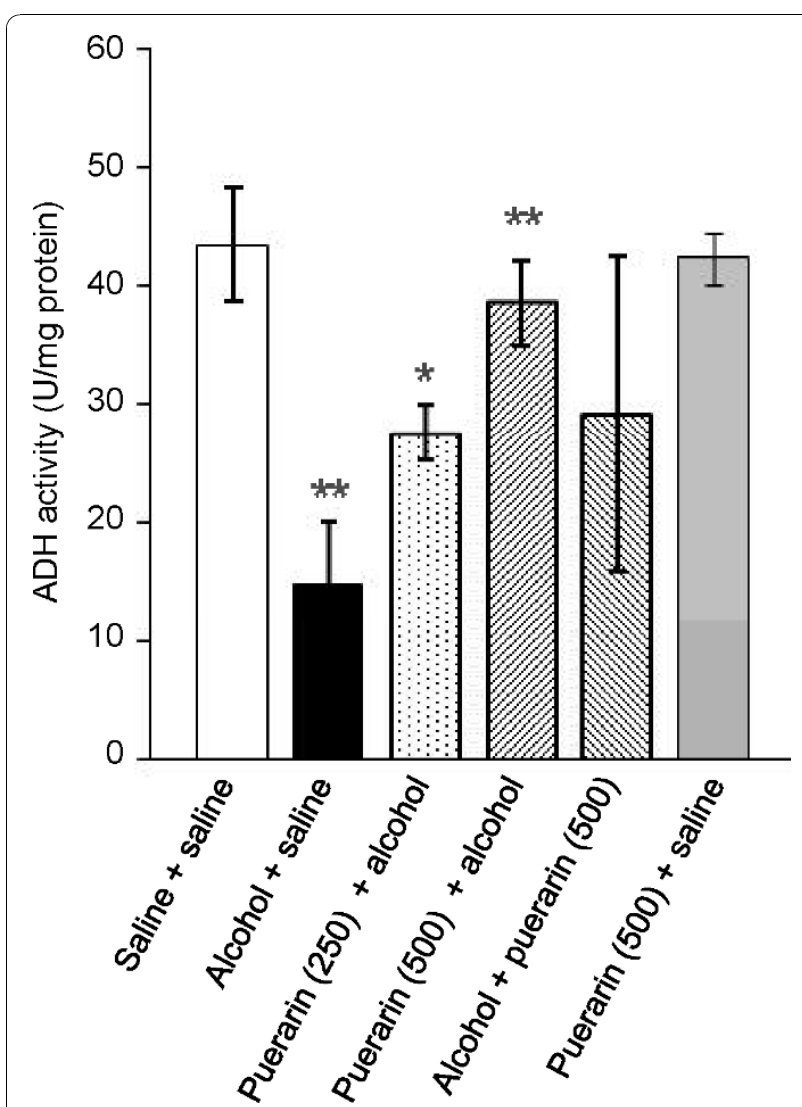

Figure 5 Puerarin increases the $\mathrm{ADH}$ activity in alcoholic mice Data are expressed as mean \pm SD $(n=8) .{ }^{*} P<0.05$ compared with 'alcohol+saline' treated group; ${ }^{* *} P<0.01$ compared with 'saline +saline' treated group.

related disorders. Puerarin pretreatment, but not posttreatment can reverse the changes of $\mathrm{GABA}_{\mathrm{A}} \mathrm{R}$ subunit expression and increase ADH activity in alcoholism models.

\section{Abbreviations}

FPE: Flos puerariae lobatae water extract; LORR: loss of righting reflex; ADH: Alcohol dehydrogenase; ALDH: aldehyde dehydrogenase; AWS: alcohol withdrawal syndromes; RPLC: Reverse-Phase Liquid Chromatography; PBS: phosphate-buffered saline; $G_{A B A} R$ : gama-aminobutyric acid type $A$ receptor.

\section{Acknowledgements}

This work was supported in part by grants from the China Natural Science Fund (30973618 to YQW), the Chinese Medicine Administration of Guangdong Province (2009177 to SL) as well as the 211 project of Jinan University. Many thanks to Dr. Du Gang of the Institute of Chinese Medical Sciences, University of Macau, for his kind assistance on quality analysis of Flos Puerariae water extract.

\section{Author details}

'Institute of New Drug Research and Guangdong Province Key Laboratory of Pharmacodynamic Constituents of Traditional Chinese Medicine \& New Drug Research, Jinan University College of Pharmacy, Guangzhou 510632, PR China. ${ }^{2}$ Division of Oral Biology \& Medicine, UCLA School of Dentistry, Los Angeles, CA 90095-1668, USA. 
Table 1 Puerarin prevents the loss of body weight in alcoholic mice

\begin{tabular}{llllllll}
\hline & & \multicolumn{5}{c}{ Body weight after days of treatment (g) } \\
Groups & $\mathbf{0}$ day & $\mathbf{2}$ days & $\mathbf{4}$ days & $\mathbf{6}$ days & $\mathbf{8}$ days & $\mathbf{1 0}$ days & $\mathbf{1 2}$ days \\
\hline Saline + saline & $20.7 \pm 1.25$ & $22.07 \pm 0.45$ & $23.87 \pm 1.03$ & $25.67 \pm 1.36$ & $27.73 \pm 1.86$ & $28.10 \pm 1.37$ & $30.37 \pm 2.06$ \\
Alcohol + saline & $22.52 \pm 0.43$ & $15.18 \pm 2.05^{* *}$ & $12.30 \pm 1.35^{* *}$ & $15.4 \pm 0.29^{* *}$ & $16.1 \pm 3.1^{* *}$ & $16.7 \pm 1.33^{* *}$ & $18 \pm 2.88^{* *}$ \\
Puerarin (250) + alcohol & $22.58 \pm 1.96$ & $18.23 \pm 2.49$ & $17 \pm 4.93$ & $18.27 \pm 2.35$ & $19.77 \pm 3.67$ & $19.43 \pm 4.39$ & $20.83 \pm 5.15^{*}$ \\
Puerarin (500) + alcohol & $24.22 \pm 0.56$ & $19.05 \pm 4.73$ & $21.68 \pm 2.22^{*}$ & $23.48 \pm 2.27^{*}$ & $24.08 \pm 1.89^{*}$ & $23.9 \pm 2.44^{*}$ & $25.23 \pm 1.4^{*}$ \\
Alcohol + puerarin (500) & $23.05 \pm 0.44$ & $19.73 \pm 3.22$ & $19.53 \pm 5.08$ & $20.55 \pm 6.3$ & $21.2 \pm 7.05$ & $22.23 \pm 3.48^{*}$ & $24.77 \pm 2.8^{*}$ \\
\hline
\end{tabular}

Data are expressed as mean \pm SD $(n=8)$. ${ }^{*} \mathrm{P}<0.05$ compared with 'alcohol+saline' treated group; ${ }^{* *} \mathrm{P}<0.05$ compared with 'saline+saline' treated group.

\section{Authors' contributions}

ZJZ, SL and JJ carried out the experiments and data analysis. ZJZ and JL interpreted the data and wrote the manuscript. YQW and PY designed the study. All authors read and approved the final version of the manuscript.

\section{Competing interests}

The authors declare that they have no competing interests.

Received: 29 May 2010 Accepted: 26 October 2010

Published: 26 October 2010

\section{References}

1. Bayard M, Mclntyre J, Hill KR, Woodside J Jr: Alcohol withdrawal syndrome. Am Fam Physician 2004, 69:1443-1450.

2. Trevisan LA, Boutros N, Petrakis IL, Krystal JH: Complications of alcohol withdrawal: pathophysiological insights. Alcohol Health Res World 1998, 22:61-66.

3. Brower KJ, Aldrich MS, Robinson EA, Zucker RA, Greden JF: Insomnia, selfmedication, and relapse to alcoholism. Am J Psychiatry 2001, 158:399-404.

4. Booth BM, Blow FC: The kindling hypothesis: further evidence from a U.S. national study of alcoholic men. Alcohol Alcohol 1993, 28:593-598.

5. Becker HC, Hale RL: Repeated episodes of ethanol withdrawal potentiate the severity of subsequent withdrawal seizures: an animal model of alcohol withdrawal "kindling". Alcohol Clin Exp Res 1993, 17:94-98.

6. Veatch LM, Gonzalez LP: Repeated ethanol withdrawal produces sitedependent increases in EEG spiking. Alcohol Clin Exp Res 1996, 20:262-267.

7. Haranaka R, Okada N, Kosoto H, Ohwada S, Hasegawa R, Nakagawa S, Kobayashi M: Effects of wu-ling-san on alcohol metabolism and alcoholic liver. J Tradit Chin Med 1985, 5:171-178.

8. Xu BJ, Zheng YN, Sung CK: Natural medicines for alcoholism treatment: a review. Drug Alcohol Rev 2005, 24:525-536.

9. Keung WM, Vallee BL: Kudzu root: an ancient Chinese source of modern antidipsotropic agents. Phytochemistry 1998, 47:499-506.

10. Lukas SE, Penetar D, Berko J, Vicens L, Palmer C, Mallya G, Macklin EA, Lee DY: An extract of the Chinese herbal root kudzu reduces alcohol drinking by heavy drinkers in a naturalistic setting. Alcohol Clin Exp Res 2005, 29:756-762.

11. Overstreet $\mathrm{DH}$, Keung WM, Rezvani AH, Massi M, Lee DY: Herbal remedies for alcoholism: promises and possible pitfalls. Alcohol Clin Exp Res 2003, 27:177-185.

12. Heyman GM, Keung WM, Vallee BL: Daidzin decreases ethanol consumption in rats. Alcohol Clin Exp Res 1996, 20:1083-1087.

13. Rooke N, Li DJ, Li J, Keung WM: The mitochondrial monoamine oxidasealdehyde dehydrogenase pathway: a potential site of action of daidzin. Med Chem 2000, 43:4169-4179.

14. Benlhabib E, Baker Jl, Keyler DE, Singh AK: Kudzu root extract suppresses voluntary alcohol intake and alcohol withdrawal symptoms in $\mathrm{P}$ rats receiving free access to water and alcohol. J Med Food 2004, 7:168-179.

15. Ariwodola OJ, Crowder TL, Grant KA, Daunais JB, Friedman DP, Weiner JL: Ethanol modulation of excitatory and inhibitory synaptic transmission in rat and monkey dentate granule neurons. Alcohol Clin Exp Res 2003, 27:1632-1639.

16. Aroor AR, Shukla SD: MAP kinase signaling in diverse effects of ethanol. Life Sci 2004, 74:2339-2364.

17. Cagetti E, Liang J, Spigelman I, Olsen RW: Withdrawal from chronic intermittent ethanol treatment changes subunit composition, reduces synaptic function, and decreases behavioral responses to positive allosteric modulators of GABAA receptors. Mol Pharmacol 2003, 63:53-64.

18. Liang J, Cagetti E, Olsen RW, Spigelman I: Altered pharmacology of synaptic and extrasynaptic GABAA receptors on CA1 hippocampal neurons is consistent with subunit changes in a model of alcohol withdrawal and dependence. J Pharmacol Exp Ther 2004, 310:1234-1245.

19. Liang J, Zhang N, Cagetti E, Houser CR, Olsen RW, Spigelman I: Chronic intermittent ethanol-induced switch of ethanol actions from extrasynaptic to synaptic hippocampal GABAA receptors. J Neurosci 2006, 26:1749-1758

20. Edenberg HJ, Xuei X, Chen HJ, Tian H, Wetherill LF, Dick DM, Almasy L, Bierut L, Bucholz KK, Goate A, et al: Association of alcohol dehydrogenase genes with alcohol dependence: a comprehensive analysis. Hum $\mathrm{Mol}$ Genet 2006, 15:1539-1549.

21. Institute of Materia Medica CAoMS: Zhong Yao Zhi Beijing; 1995.

22. Boehm SL, Ponomarev I, Jennings AW, Whiting PJ, Rosahl TW, Garrett EM, Blednov YA, Harris RA: gamma-Aminobutyric acid A receptor subunit mutant mice: new perspectives on alcohol actions. Biochem Pharmacol 2004, 68:1581-1602.

23. Liang J, Suryanarayanan A, Abriam A, Snyder B, Olsen RW, Spigelman I: Mechanisms of reversible GABAA receptor plasticity after ethanol intoxication. J Neurosci 2007, 27:12367-12377.

24. Liang JH, Chen F, Krstew E, Cowen MS, Carroll FY, Crawford D, Beart PM, Lawrence AJ: The GABA(B) receptor allosteric modulator CGP7930, like baclofen, reduces operant self-administration of ethanol in alcoholpreferring rats. Neuropharmacology 2006, 50:632-639.

25. McGregor NR: Pueraria lobata (Kudzu root) hangover remedies and acetaldehyde-associated neoplasm risk. Alcohol 2007, 41:469-478.

26. Zhang JF, Lu YX, Qiu XX, Fang Y: Relationship between alcohol drinking and alcohol-related health problems. Biomed Environ Sci 2004, 17:196-202.

27. Lin RC, Li TK: Effects of isoflavones on alcohol pharmacokinetics and alcohol-drinking behavior in rats. Am J Clin Nutr 1998, 68:1512S-1515S.

28. Overstreet DH, Lee YW, Rezvani AH, Pei YH, Criswell HE, Janowsky DS: Suppression of alcohol intake after administration of the Chinese herbal medicine, NPI-028, and its derivatives. Alcohol Clin Exp Res 1996, 20:221-227.

29. Keung WM, Vallee BL: Daidzin: a potent, selective inhibitor of human mitochondrial aldehyde dehydrogenase. Proc Natl Acad Sci USA 1993, 90:1247-1251.

30. Keung WM: Biochemical studies of a new class of alcohol dehydrogenase inhibitors from Radix puerariae. Alcohol Clin Exp Res 1993, 17:1254-1260.

31. Keung WM, Lazo O, Kunze L, Vallee BL: Daidzin suppresses ethanol consumption by Syrian golden hamsters without blocking acetaldehyde metabolism. Proc Natl Acad Sci USA 1995, 92:8990-8993.

32. Fernandez-Sola J, Preedy VR, Lang CH, Gonzalez-Reimers E, Arno M, Lin JC, Wiseman H, Zhou S, Emery PW, Nakahara T, et al: Molecular and cellular events in alcohol-induced muscle disease. Alcohol Clin Exp Res 2007, 31:1953-1962.

33. Singal AK, Anand BS: Mechanisms of synergy between alcohol and hepatitis C virus. J Clin Gastroenterol 2007, 41:761-772.

34. Song BJ, Moon KH, Olsson NU, Salem N Jr: Prevention of alcoholic fatty liver and mitochondrial dysfunction in the rat by long-chain polyunsaturated fatty acids. J Hepatol 2008, 49:262-273.

35. Sancho-Tello M, Muriach M, Barcia J, Bosch-Morell F, Genoves JM, JohnsenSoriano S, Romero B, Almansa I, Diaz-Llopis M, Garcia-Delpech S, et al: 
Chronic alcohol feeding induces biochemical, histological, and functional alterations in rat retina. Alcohol Alcohol 2008, 43:254-260.

36. Warnakulasuriya S, Parkkila S, Nagao T, Preedy VR, Pasanen M, Koivisto H, Niemela O: Demonstration of ethanol-induced protein adducts in oral leukoplakia (pre-cancer) and cancer. J Oral Pathol Med 2008, 37:157-165.

37. Li Y, Walker DW, King MA: Peroxide mediates ethanol-induced cytotoxicity in PC12 cells. Free Radic Biol Med 2001, 30:389-392.

38. Lockhart B, Jones C, Cuisinier C, Villain N, Peyroulan D, Lestage P: Inhibition of L-homocysteic acid and buthionine sulphoximine-mediated neurotoxicity in rat embryonic neuronal cultures with alpha-lipoic acid enantiomers. Brain Res 2000, 855:292-297.

39. Cao X, Tian Y, Zhang T, Li X, Ito Y: Separation and purification of isoflavones from Pueraria lobata by high-speed counter-current chromatography. J Chromatogr A 1999, 855:709-713.

doi:10.1186/1749-8546-5-36

Cite this article as: Zhang et al.: Preventive effects of Flos Perariae (Gehua) water extract and its active ingredient puerarin in rodent alcoholism models. Chinese Medicine 2010 5:36.

\section{Submit your next manuscript to BioMed Central} and take full advantage of:

- Convenient online submission

- Thorough peer review

- No space constraints or color figure charges

- Immediate publication on acceptance

- Inclusion in PubMed, CAS, Scopus and Google Scholar

- Research which is freely available for redistribution

Submit your manuscript at www.biomedcentral.com/submit
C Biomed Central 